\title{
Vanadium lons in Sol-Gel Silica Studied by Electron Spin Resonance, UV-Visible Absorption, Diffuse Reflectance, and Photoluminescence Spectroscopies
}

\author{
Michiyo KAWASHIMA, Nobuhiro ODA, Yoshikuni UCHIDA and Kazunori MATSUI \\ Department of Industrial Chemistry, College of Engineering, Kanto Gakuin University, \\ 4834, Mutsuura-cho, Kanazawa-ku, Yokohama-shi 236-8501 \\ ESR, 紫外一可視吸収, 拡散反射, ホトルミネッセンス分光法による \\ ゾルーゲルシリカ中のバナジウムイオンの研究 \\ 川島道代·小田伸浩·内田佳邦 ·松井和則 \\ 関東学院大学工学部工業化学科, 236-8501 横浜市金沢区六浦町 4834
}

\begin{abstract}
Valence states and structures of vanadium species supported on silica, which were synthesized by a sol-gel method, were studied by Electron Spin Resonance (ESR), UV-visible absorption, diffuse reflectance, and photoluminescence spectroscopies for various stages of the process (sols, xerogels and heated xerogels). ESR measurements revealed that $\mathrm{V}^{4+}$ ions were present as $\left[\mathrm{VO}\left(\mathrm{H}_{2} \mathrm{O}\right)_{5}\right]^{2+}$ in sols and xerogels for a lower vanadium concentration, whereas a higher vanadium concentration led to the aggregation of $\mathrm{V}^{4+}$ ions in the drying stage of the sol-gel process. Upon calcinations at a higher temperature of $873 \mathrm{~K}$, the $\mathrm{V}^{4+}$ ions were oxidized to $\mathrm{V}^{5+}$ which, for a lower vanadium concentration, were located in isolated pseudotetrahedral silica sites, and with an increase in the vanadium content, were aggregated so that $\mathrm{V}_{2} \mathrm{O}_{5}$ was finally formed. Changes of pseudotetrahedral structure to octahedral one by the coordination of water molecules in the atmosphere were observed, especially when the xerogels was heated at a lower temperature of $973 \mathrm{~K}$.
\end{abstract}

[Received October 10, 2001; Accepted March 25, 2002]

Key-words : Vanadium ions, Sol-gel silica, ESR, UV-visible absorption, Photoluminescence

1. Introduction

Supported vanadium oxide is an intriguing material because of its catalytic and photocatalytic applications. ${ }^{1-5)}$ A clue for understanding their properties can be attained through a knowledge of the structures of vanadia. Therefore there' have been many studies on them by using various spectroscopic methods. ${ }^{6)}$-15) Among them, the photoluminescence of pentavalent vanadium $\left(\mathrm{V}^{5+}\right)$ ions supported on silica is of quite interest.1),3),16)-18) The photoluminescence at $77 \mathrm{~K}$ had the vibrational progression of $1050 \mathrm{~cm}^{-1}$ and the lifetime of about $20 \mathrm{~ms}$, for which it was assigned to the phosphorescence from the lowest triplet state of the pseudotetrahedral oxovanadium chromophore. ${ }^{16)}$ The pseudotetrahedral oxovanadium has three basal-plane oxygens and a terminal double bonded oxygen. The lowest triplet state was generally attributed to the ligand-to-metal charge transfer (CT) state associated with the $\mathrm{V}=\mathrm{O}$ bond.1),3),16) A recent study, on the contrary, argued that the lowest excited triplet state possibly involved promotion of an electron from the basal plane ligands $(\mathrm{O})$ to the metal center $\left(\mathrm{V}^{5+}\right)$ and not from the terminal $\mathrm{V}=\mathrm{O}$ bond. ${ }^{18)}$ The nature of the triplet state is still an open question.

The synthesis of the silica-supported vanadium oxide is employed by using a sol-gel process, ${ }^{12), 14), 15), 18)-21)}$ which makes it possible to study the formation mechanisms and structures of vanadium species at molecular scale by the sol-gel process. In our previous reports, we characterized with Electron Spin Resonance (ESR) technique tetravalent vanadium $\left(\mathrm{V}^{4+}\right)$ ion-doped silica through sol-to-gel transformation, ${ }^{19)}$ and studied optical properties of the pseudotetrahedral oxovanadium chromophores supported on silica after heat treatment of the dried gels. ${ }^{20)}$ In this paper, we shall report in detail valence states and structures of the vanadium species in silica from sols to heated gels via a drying process, by means of several spectroscopic tech- niques.

\section{Experimental}

The following reagents were used without additional purification: $\mathrm{VOSO}_{4} \cdot 2 \mathrm{H}_{2} \mathrm{O}$ (Kojundo Chem. Labo.), tetramethoxysilane (TMOS; Tokyo Kasei Kogyo), methanol (Katayama Chem. Ind.), and $\mathrm{HCl}$ (Wako Pure Chem. Ind.). Water was deionized and distilled. An aqueous solution of $\mathrm{VOSO}_{4} \cdot 2 \mathrm{H}_{2} \mathrm{O}(7.2 \mathrm{ml})$ and $2.0 \mathrm{ml}$ of $1 \mathrm{M} \mathrm{HCl}$ were mixed, to which TMOS dissolved in methanol $(15 \mathrm{ml} / 15 \mathrm{ml})$ was added. The molar ratio of TMOS: water was 1:5. In the following the nominal amount of vanadium (V) ions in silica gel is expressed as 100 times of the molar ratio of $\mathrm{V} / \mathrm{Si}$. The mixtures were stirred for $0.5 \mathrm{~h}$ and allowed to be gelled at room temperature in polystyrene beakers sealed by a plastic film with several pinholes. The resultant gels were dried in the polystyrene beakers in air at room temperature over 3 months. They were further calcined from 873 to $1273 \mathrm{~K}$ for $1-4 \mathrm{~h}$ in air.

ESR spectra measurements were performed at $296 \mathrm{~K}$ with a JEOL JES-RE1X spectrometer using $\mathrm{X}$ band. The microwave power was $30 \mathrm{~mW}$ and the modulation amplitude, $0.2 \mathrm{mT}$. A Mn marker was used to calibrate a magnetic field. Diffuse reflectance UV-visible spectra: were taken at room temperature on a JASCO V-570 spectrophotometer. Steady-state luminescence spectra were recorded at $77 \mathrm{~K}$ on a JASCO FP-770 spectrofluorometer. Luminescence decay profiles were obtained with a $\mathrm{N}_{2}$ laser (Usho AN-200) and a photomultiplier (Hamamatsu Photonics R955).

\section{Results and discussion}

3.1. Valence-states and coordination number of vanadium ions in silica

Figure 1 shows the ESR spectra of $\mathrm{V}^{4+}$-doped sols and xerogels dried over 3 months under the various $\mathrm{V}: \mathrm{Si}$ molar 


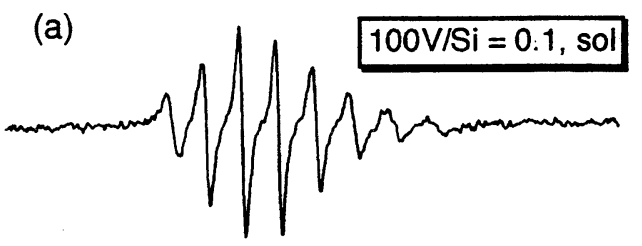

(b)
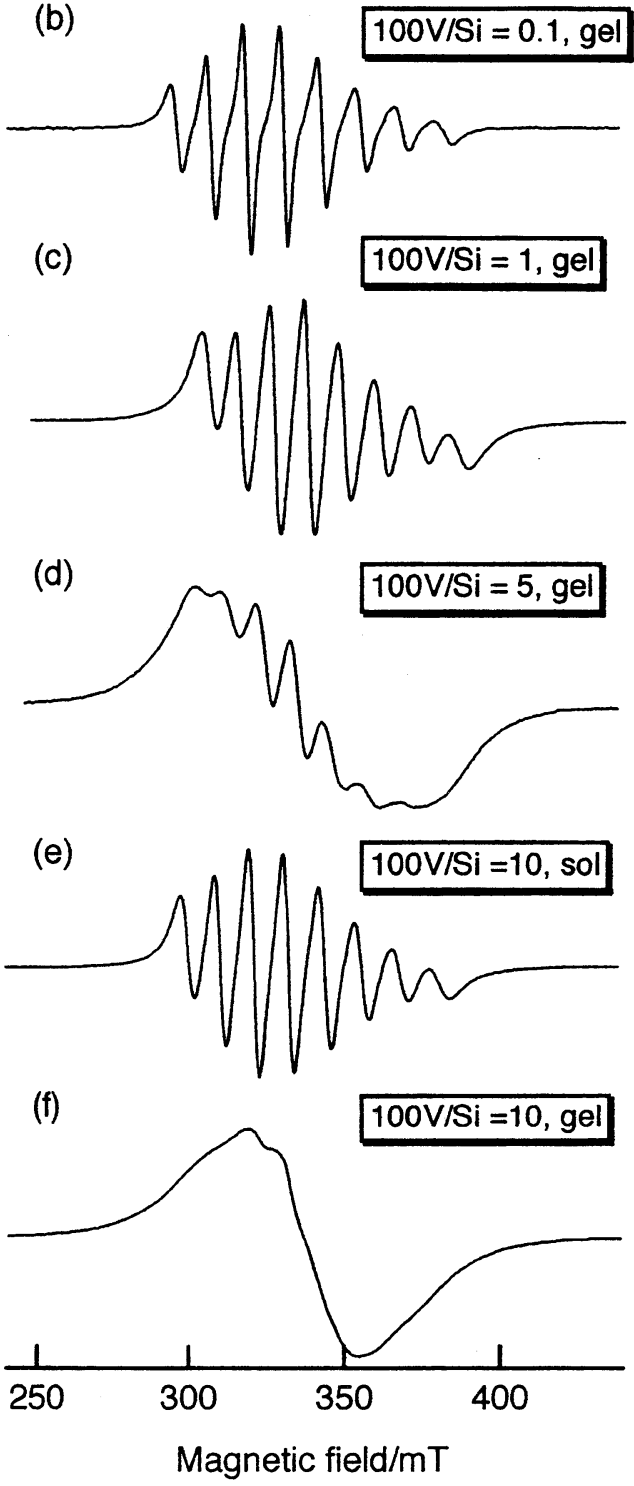

Fig. 1. ESR spectra of $\mathrm{V}^{4+}$-doped silica sols just prepared and xerogels dried over 3 months for various $\mathrm{V}$ concentrations.

ratios. Eight lines of a hyperfine structure $\left(A_{\mathrm{av}}=11.2 \mathrm{mT}\right)$ assignable to $\left[\mathrm{VO}\left(\mathrm{H}_{2} \mathrm{O}\right)_{5}\right]^{2+}$ were observed in the spectrum of the sol at $100 \mathrm{~V} / \mathrm{Si}=0.1$ (a), which arose from the almost complete averaging of $\mathrm{g}$ anisotropy owing to the "tumbling motion" of the $\left[\mathrm{VO}\left(\mathrm{H}_{2} \mathrm{O}\right)_{5}\right]^{2+} .{ }^{19)}$,21) A very similar ESR spectrum was also observed for the dried sample (b), indicating that the tumbling motions in the silica gel pores were as fast as those in sols. As shown in the previous paper, ${ }^{19)}$ this fast motion ceased when the xerogels were dehydrated in vacuum and started again after the dehydrated xerogels were left in the ambient atmosphere for a day or so. These results showed that $\mathrm{V}^{4+}$ ions were not directly bonded with the siloxane network structure but trapped as $\left[\mathrm{VO}\left(\mathrm{H}_{2} \mathrm{O}\right)_{5}\right]^{2+}$ in the silica gel pores. With increasing $\mathrm{V}$

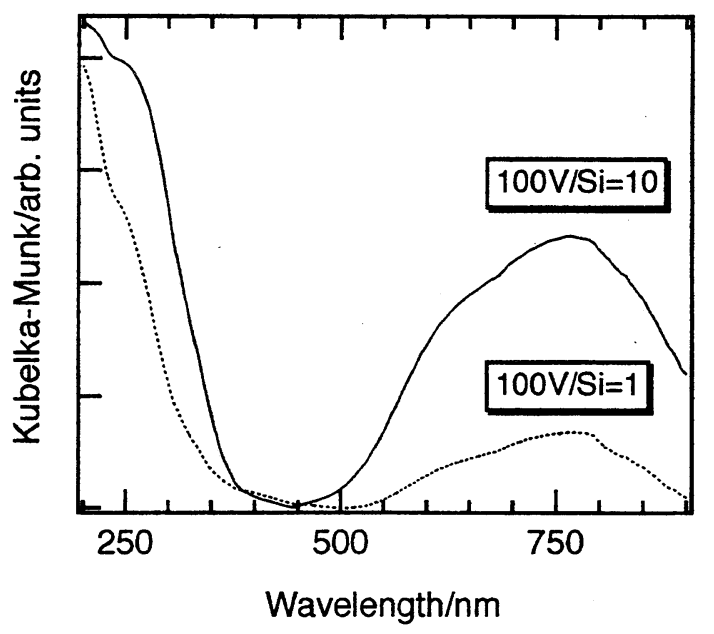

Fig. 2. Absorption spectra of xerogels dried over 3 months at 100 $\mathrm{V} / \mathrm{Si}=1$ and 10 .

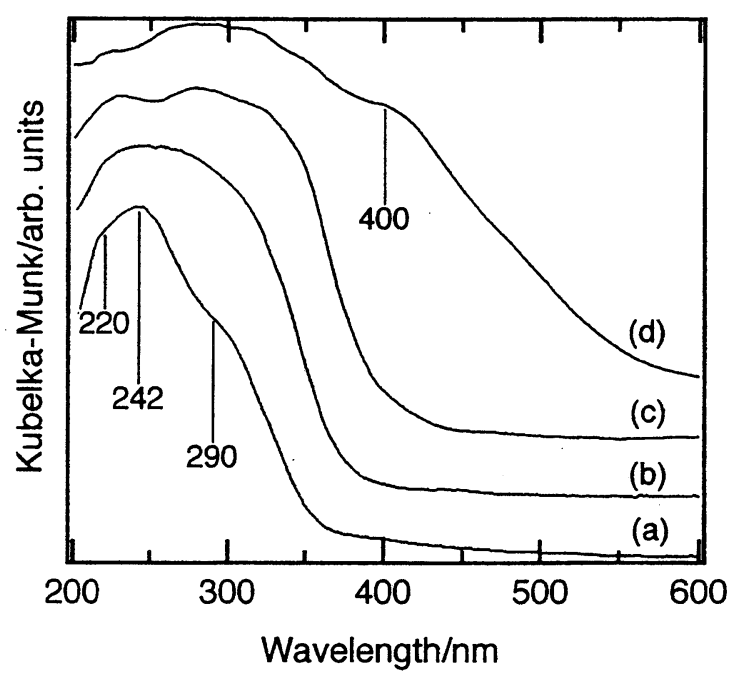

Fig. 3. Diffuse reflectance UV-visible spectra of samples heated at $1273 \mathrm{~K}$ for $4 \mathrm{~h}$ for various $\mathrm{V}$ concentrations: $100 \mathrm{~V} / \mathrm{Si}=0.1$ (a), 1 (b), 5 (c) and 10 (d).

concentration, a broad signal overlapped with the well-defined signal came to be observed for the xerogels; it slightly appeared at $100 \mathrm{~V} / \mathrm{Si}=1$ (c) and became predominant at $100 \mathrm{~V} / \mathrm{Si}=5(\mathrm{~d})$. The broad signal with $g \approx 1.98$ is attributed to aggregations of $\mathrm{V}^{4+}$ ions. ${ }^{4), 21)}$ Moreover, the fact that the broad signal was scarcely observed for the sol (e) and the wet gel (not shown here), even at $100 \mathrm{~V} / \mathrm{Si}=10$ but became significant for the xerogel dried over 3 months (f) indicate that the aggregations were formed during the drying stage of gels. Figure 2 shows the absorption spectra for the xerogels at $100 \mathrm{~V} / \mathrm{Si}=1$ and 10 . A broad absorption band at $760 \mathrm{~nm}$ accompanying with a shoulder around 640 $\mathrm{nm}$ were obtained, which is ascribed to oxo-vanadium complexes of $\left[\mathrm{VO}\left(\mathrm{H}_{2} \mathrm{O}\right)_{5}\right]^{2+}$.14),15) There seems to be no clear indication of a new band due to aggregations in contrast to the ESR spectra in Fig. 1.

With thermal treatment in air the ESR signals due to $\mathrm{V}^{4+}$ decreased and became undetectable above $873 \mathrm{~K}$, corresponding to which the absorption band with a peak at 760 $\mathrm{nm}$ due to $\left[\mathrm{VO}\left(\mathrm{H}_{2} \mathrm{O}\right)_{5}\right]^{2+}$ disappeared. Figure 3 shows the 
absorption spectra of the samples heated at $1273 \mathrm{~K}$ for $4 \mathrm{~h}$ with various $\mathrm{V}$ concentrations. The spectrum of $100 \mathrm{~V} / \mathrm{Si}=$ 0.1 (a) exhibited a peak at $242 \mathrm{~nm}$ and shoulders at 220 and $290 \mathrm{~nm}$. The spectrum is very close to previous results, ${ }^{3), 9)}$ where these bands were generally assigned to the oxygento-vanadium charge transfer (CT) transitions in dispersed pseudotetrahedral $\mathrm{V}^{5+}$. The appearance of the blue-shifted band at $220 \mathrm{~nm}$ as well as the main peak at $242 \mathrm{~nm}$ suggests the presence of more distorted pseudotetracoordinated $\mathrm{V}^{5+}$ (band at $220 \mathrm{~nm}$ ) in addition to the dominant pseudotetracoordinated $\mathrm{V}^{5+}$ (band at $242 \mathrm{~nm}$ ). $\left.{ }^{9)}, 22\right)$ With increasing the $\mathrm{V}$ concentration, a spectral broadening and shift to longer wavelength were observed at $100 \mathrm{~V} / \mathrm{Si}=1$ (b) and 5 (c). These changes can be ascribed to the aggregations of pseudotetrahedral $\mathrm{V}^{5+}$, because isolated species generally give rise to CT transitions in a higher energy range than polymeric species as explained by the size effects. ${ }^{7}$ In addition, a broad band at around $400 \mathrm{~nm}$ appeared at $100 \mathrm{~V} / \mathrm{Si}=10$ (d). The visible band agrees with that of $\mathrm{V}_{2} \mathrm{O}_{5}$ in vanadia-silica systems.3),7),9),23) Small microcrystalline domains of $\mathrm{V}_{2} \mathrm{O}_{5}$ were found at higher concentrations in vanadia-silica prepared by the sol-gel process. ${ }^{4), 23), 24)}$ Actually the X-ray diffraction pattern of the calcined gel showed weak reflections at $2 \theta=21.5^{\circ}$ and $26.1^{\circ}$ corresponding to the crystalline $\mathrm{V}_{2} \mathrm{O}_{5} \cdot{ }^{24)}$ Considering these results together, the formation of $\mathrm{V}_{2} \mathrm{O}_{5}$ at $100 \mathrm{~V} / \mathrm{Si}=10$ can be concluded. These spectral changes with an increase in the $\mathrm{V}$ concentrations coincide with the broad signal in the ESR spectra thus confirming that the concentrated $\mathrm{V}^{4+}$ in the dried gels was converted to the aggregations of pseudotetrahedral $\mathrm{V}^{5}+$ ions $(100 \mathrm{~V} / \mathrm{Si}=$ $5)$ and $\mathrm{V}_{2} \mathrm{O}_{5}(100 \mathrm{~V} / \mathrm{Si}=10)$ after calcinations. In aqueous solutions, a variety of $\mathrm{V}^{5+}$ species can be formed, depending on the solution $\mathrm{pH}$ and vanadium oxide concentration; namely, more polymerized and complex vanadium oxide species such as $\mathrm{V}_{10} \mathrm{O}_{26}(\mathrm{OH})_{2}{ }^{4-}$ and crystalline $\mathrm{V}_{2} \mathrm{O}_{5}$ are formed with decreasing the solution $\mathrm{pH}$ or increasing the vanadium oxide concentration. ${ }^{25}$ ) Therefore, the several species found in this experiment are not unexpected.

\subsection{Phosphorescence properties of silica-supported} vanadium oxide

Figure 4 shows the phosphorescence spectra of the samples heated at $1273 \mathrm{~K}$ for $4 \mathrm{~h}$ with various $\mathrm{V}$ concentrations. The spectra became blurred gradually and the intensities decreased with an increase in the $\mathrm{V}$ content. At $100 \mathrm{~V} / \mathrm{Si}=$ 10 (e), the spectrum showed the poorly resolved structure and had a shifted peak at $558 \mathrm{~nm}$ with the intensity of about one twentieth of that at $100 \mathrm{~V} / \mathrm{Si}=0.1$ (a). These spectra changes coincided with those found in the absorption spectra shown in Fig. 3. Based on the absorption spectra, the red shifted and blurred vibrational structure in the phosphorescence can be ascribed to the formation of aggregated pseudotetrahedral $\mathrm{V}^{5+}$. The decreased phosphorescence intensity is attributed to decreasing of the isolated pseudotetrahedral $\mathrm{V}^{5}+$ due to the formation of aggregated pseudotetrahedral $\mathrm{V}^{5+}$ and $\mathrm{V}_{2} \mathrm{O}_{5}$, because the phosphorescence was observed for tetrahedral vanadium species dispersed on silica but not for bulk $\mathrm{V}_{2} \mathrm{O}_{5}$. 3 )

The phosphorescence lifetimes were obtained from the decay curves monitored at the phosphorescence peaks. The lifetimes can be fitted by a sum of two exponential decays (Eq. 1):

$$
I(t)=A_{1} \exp \left(-t / \tau_{1}\right)+A_{2} \exp \left(-t / \tau_{2}\right),
$$

where $A_{1}+A_{2}=1$. Table 1 shows the lifetimes of two decays $\left(\tau_{1}\right.$ and $\left.\tau_{2}\right)$ and the relative weights of each component $\left(A_{1}\right.$ and $\left.A_{2}\right)$ as well as the phosphorescence peaks. The longer lifetime component $\left(A_{1}\right)$ with approximately 10 $\mathrm{ms}$ was dominant for the concentration $100 \mathrm{~V} / \mathrm{Si} \leq 1$. The $A_{1}$ component gradually decreased with the increased $\mathrm{V}$

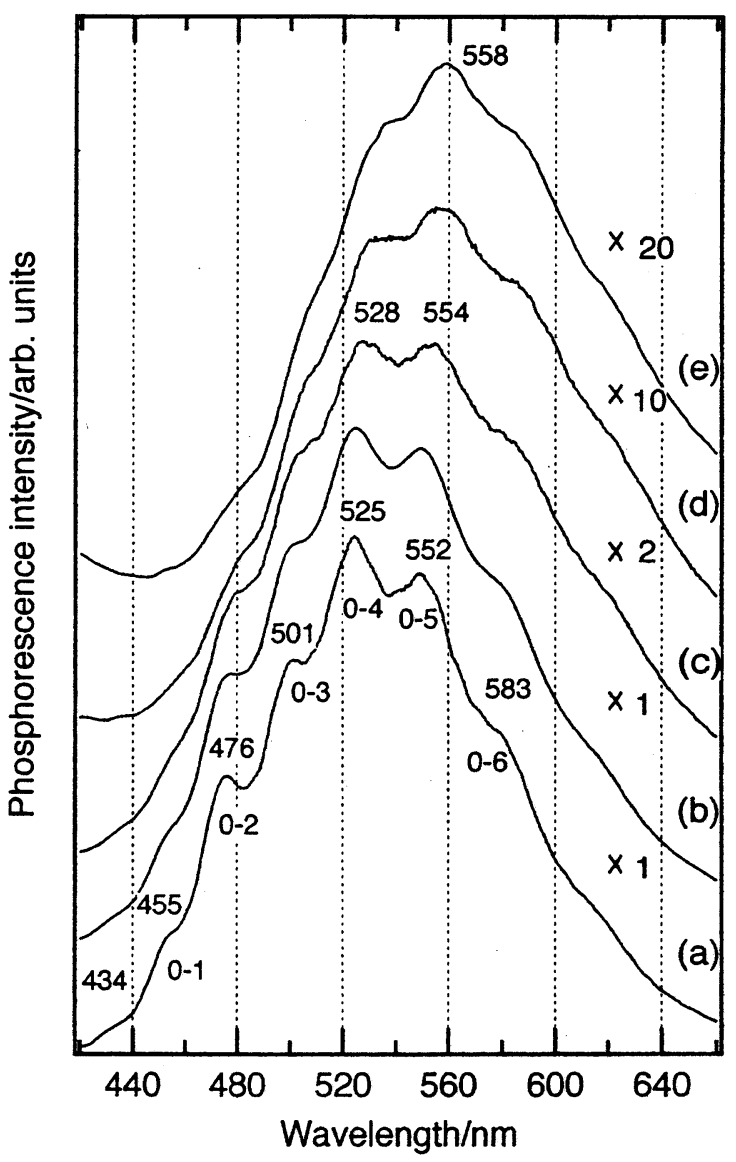

Fig. 4. Phosphorescence spectra of samples heated at $1273 \mathrm{~K}$ for $4 \mathrm{~h}$ at $350-\mathrm{nm}$ excitation for various $\mathrm{V}$ concentrations: $100 \mathrm{~V} / \mathrm{Si}=$ 0.1 (a), 1 (b), 5 (c), 9 (d) and 10 (e).

Table 1. Long $\left(\tau_{1}\right)$ and Short $\left(\tau_{2}\right)$ Lifetimes with Preexponential Factors $A_{1}$ and $A_{2}$ (in Parentheses) for Phosphorescence Peaks of Various Vanadium Oxide in $\mathrm{SiO}_{2}$ Calcined at $1273 \mathrm{~K}$ and Observed at $77 \mathrm{~K}$

\begin{tabular}{llll}
\hline $100 \mathrm{~V} / \mathrm{Si}$ & $\lambda \max / \mathrm{nm}$ & $\tau_{1} / \mathrm{ms}\left(\mathrm{A}_{1}\right)$ & $\tau_{2} / \mathrm{ms}\left(\mathrm{A}_{2}\right)$ \\
\hline 0.1 & 524 & $10.8(0.76)$ & $2.2(0.24)$ \\
1 & 525 & $10.0(0.68)$ & $2.5(0.32)$ \\
3 & 527 & $8.4(0.64)$ & $1.5(0.36)$ \\
5 & 528 & $7.8(0.56)$ & $1.2(0.44)$ \\
9 & 555 & $5.5(0.45)$ & $0.5(0.55)$ \\
10 & 558 & $4.9(0.54)$ & $0.4(0.46)$ \\
\hline
\end{tabular}

contents and the lifetime was finally $4.9 \mathrm{~ms}$ at $100 \mathrm{~V} / \mathrm{Si}=$ 10. The lifetime of the $A_{2}$ component also diminishes from 2 to $0.4 \mathrm{~ms}$. The decrease in the lifetimes corresponded well to the decrease in the phosphorescence intensity, suggesting the concentration quenching owing to the aggregations of pseudotetrahedral oxovanadium chromophores.

In Table 2, the wavelengths $(v)$ and the vibrational frequencies $\left(\Delta v_{j-1, j}\right)$ are summarized for samples calcined at 1173 and $1273 \mathrm{~K}$ for $4 \mathrm{~h}$ as examples of comparatively resolved spectra. The average vibrational frequency from the $0-1$ to $0-3$ bands was $\sim 1040 \mathrm{~cm}^{-1}$, which is quite good agreement with that of the $\mathrm{V}=\mathrm{O}$ stretching band.1),3),16),17) On the other hand, the vibrational frequency through the $0-4$ and $0-6$ bands was reduced in comparison with that in lower order of vibrational transitions and the average of all 
Table 2. Vibrational Frequencies of the Phosphorescence Spectra at $77 \mathrm{~K}$ from Vanadium Oxide in $\mathrm{SiO}_{2}(100 \mathrm{~V} / \mathrm{Si}=0.1)$ Calcined at (a) $1173 \mathrm{~K}$ and (b) $1273 \mathrm{~K}$

\begin{tabular}{lll}
\hline$\lambda / \mathrm{nm}$ & $v / \mathrm{cm}^{-1}$ & $\begin{array}{l}\Delta v_{0, j} / \mathrm{cm}^{-1} \\
\left(\Delta v_{0, j-1}+\Delta v_{\mathrm{i}-1, j}\right)\end{array}$ \\
\hline (a) & & \\
$432(0-0)$ & 23148 & 0 \\
$453(0-1)$ & 22075 & 1073 \\
$475(0-2)$ & 21053 & $2095(1073+1022)$ \\
$500(0-3)$ & 20000 & $3148(2095+1053)$ \\
$524(0-4)$ & 19084 & $4064(3148+916)$ \\
$551(0-5)$ & 18149 & $4999(4064+935)$ \\
$580(0-6)$ & 17241 & $5907(4999+908)$ \\
$(\mathrm{b})$ & & \\
$434(0-0)$ & 23041 & 0 \\
$455(0-1)$ & 21978 & 1063 \\
$476(0-2)$ & 21008 & $2033(1063+970)$ \\
$501(0-3)$ & 19960 & $3081(2033+1048)$ \\
$525(0-4)$ & 19048 & $3993(3081+912)$ \\
$552(0-5)$ & 18116 & $4925(3993+932)$ \\
$583(0-6)$ & 17153 & $5888(4925+963)$ \\
\hline
\end{tabular}

was $\sim 980 \mathrm{~cm}^{-1}$. According to Tran et al.,18) the averaged frequency corresponded to the vibrational band at $977 \mathrm{~cm}^{-1}$ attributed to a basal plane $\mathrm{V}-\mathrm{O}$ stretching mode. However, it is not necessarily adequate to analyze the spectrum by using the average frequency of all bands, because there may be the anharmonicity of the potential for the higher overtone. Therefore, it seems to be preferable to consider that the phosphorescence spectrum consists of the progression of the $\mathrm{V}=\mathrm{O}$ stretching.

The calcination temperature influenced the stability of the phosphorescent species. Figure 5 (a) shows the phosphorescence spectra of a sample at $100 \mathrm{~V} / \mathrm{Si}=0.1$ measured just after heating at $973 \mathrm{~K}$ and after exposing to be moist air for $3 \mathrm{~h}$. The spectral form of the phosphorescence did not change essentially after $3 \mathrm{~h}$ but the intensity reduced to $20 \%$ of the initial one, whereas the excitation spectrum corresponding to the $\mathrm{CT}$ bands of $\mathrm{V}^{5+}$ in the pseudotetrahedral coordination showed a decrease in the relative intensity of the $290-\mathrm{nm}$ band against the $240-\mathrm{nm}$ band with the exposure time as shown in Fig. 5(b). Figure 6 shows the absorption spectra of the corresponding samples shown in Fig. 5 measured just after heating at $973 \mathrm{~K}$ and successively exposing to the moist air for $3 \mathrm{~h}$. The spectrum of the dehydrated sample had a peak at $244 \mathrm{~nm}$ with a shoulder at $290 \mathrm{~nm}$, which decreased in intensity with accompanying an increased tail above $350 \mathrm{~nm}$ after $3 \mathrm{~h}$. These spectral changes were ascribed to the formation of octahedral $\mathrm{V}^{5+}$ due to the coordination of water molecules.7),12) Therefore, the decrease in the phosphorescence intensity observed in Fig. 5 (a) can be attributed to a decrease in the pseudotetrahedral $\mathrm{V}^{5+}$ species. Longer wavelength phosphorescence can be expected from the octahedral $\mathrm{V}^{5+}$ species for the hydrated samples if emissive. However, no luminescence was observed when excited at the 450-nm band of the octahedral $\mathrm{V}^{5+}$ species. This can be explained by an increase in the radiationless transition (energy gap law). ${ }^{26}$ )

3.3 Structural change of vanadium species in silica

Based on the ESR, UV-visible absorption, and phosphorescence data, the plausible structures for the $\mathrm{V}$ species are summarized in Fig. 7. The hydrated vanadyl species in sols and xerogels are $\left[\mathrm{VO}\left(\mathrm{H}_{2} \mathrm{O}\right)_{5}\right]^{2+}$ (A) for low vanadium concentration. The very fast tumbling motion of [VO $\left.\left(\mathrm{H}_{2} \mathrm{O}\right)_{5}\right]^{2+}(\mathrm{A})$ for sols and xerogels observed with ESR
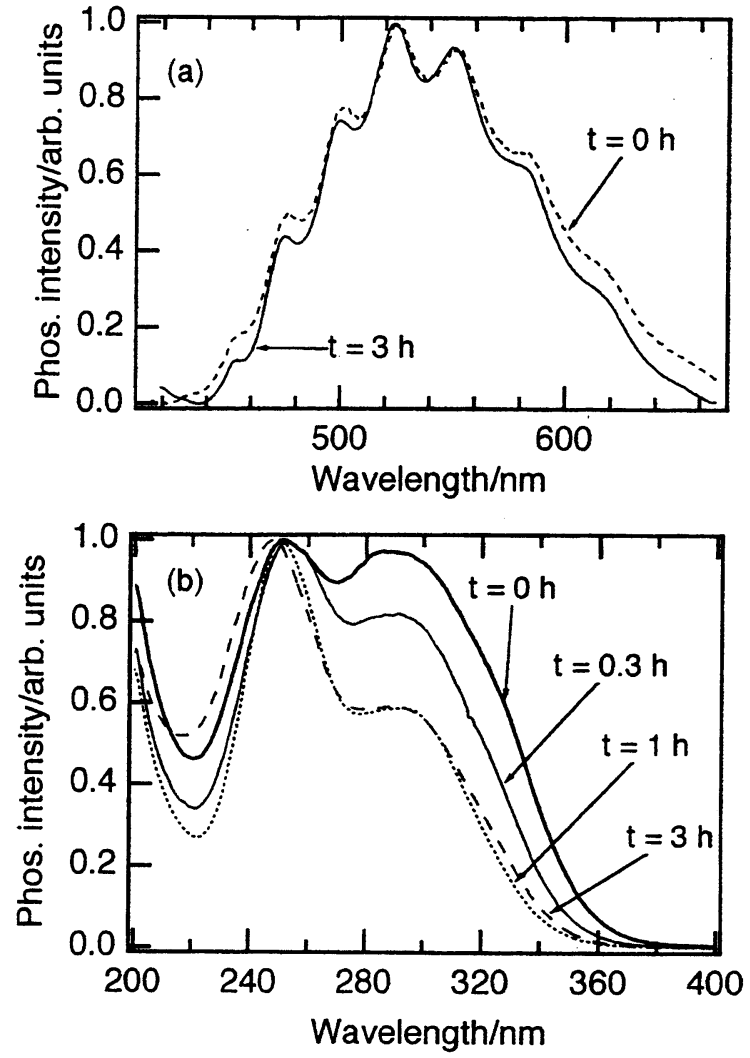

Fig. 5. Phosphorescence (a) and excitation (b) spectra of a sample at $100 \mathrm{~V} / \mathrm{Si}=0.1$ measured just after heating at $973 \mathrm{~K}$ and after exposing to the atmospheric humidity to $3 \mathrm{~h}$.

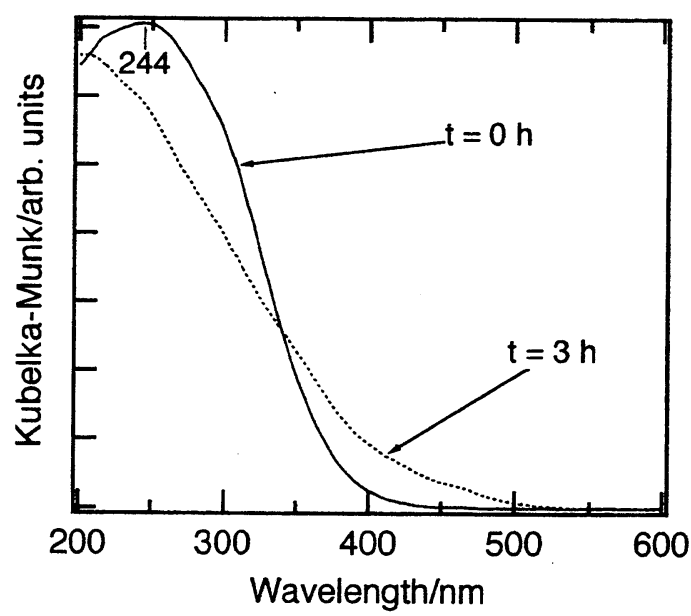

Fig. 6. Diffuse reflectance UV-visible spectra of a sample at 100 $\mathrm{V} / \mathrm{Si}=0.1$ measured just after heating at $973 \mathrm{~K}$ and after exposing to the atmospheric humidity for $3 \mathrm{~h}$.

technique indicate that there is little direct bonding between the vanadyl species and silica surface. After calcination, vanadium is oxidized to $\mathrm{V}^{5+}$ in dispersed pseudotetrahedral silica site (B) which shows the phosphorescence. Water molecules can coordinate in $\mathrm{V}^{5+}$ to form the octahedral species (C) in air humidity as seen in the spectral changes in the phosphorescence excitation and absorption spectra. Aggregates of vanadyl species (D) are formed for higher vanadium concentration in the drying stage of the sol-gel 
<smiles>O=[PH](O)(O)(O)OCCO</smiles>

(A)<smiles></smiles>

(B)<smiles>O=[PH](O)(O[SiH3])(O[SiH3])O[SiH3]</smiles>

(C)

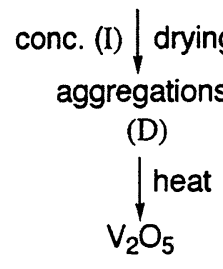

(D) $\mathrm{V}_{2} \mathrm{O}_{5}$
(E)<smiles>O=[N+](O[Si])O[N+](=O)O[Si]([Si])(O[Si])O[Si]</smiles>

Fig. 7. Schematic structural changes proposed for vanadium species in sol, xerogel and heated gels.

process, resulting in a broad ESR signal. One of the possible structure will be a hydroxo-bridged like. On calcination, the aggregates change to pseudotetrahedral $\mathrm{V}^{5+}$ aggregates (E) and $\mathrm{V}_{2} \mathrm{O}_{5}$ for further high vanadium concentration.

\section{Conclusions}

The $\mathrm{V}^{4+}$ ions were present as $\left[\mathrm{VO}\left(\mathrm{H}_{2} \mathrm{O}\right)_{5}\right]^{2+}$ in the sols and xerogels of silica for lower vanadium concentration. The aggregates of $\mathrm{V}^{4+}$ ions were formed for higher vanadium concentration in the drying stage of the sol-gel process. After calcination above $873 \mathrm{~K}$, they were oxidized to $\mathrm{V}^{5+}$ in dispersed pseudotetrahedral silica site, which showed the phosphorescence spectra with the vibrational progression associated with the $\mathrm{V}=\mathrm{O}$ bond. By the coordination of water molecules the pseudotetrahedral structure was changed to the octahedral one and the phosphorescence intensity was reduced. This phenomenon was particularly observed when calcined below $973 \mathrm{~K}$. It was also clarified from the results of the phosphorescence and lifetime measurements that the aggregates of $\mathrm{V}^{4+}$ ions change to pseudotetrahedral $\mathrm{V}^{5+}$ aggregates and crystalline $\mathrm{V}_{2} \mathrm{O}_{5}$ after calcinations.

\section{References}

1) Patterson, H. H., Cheng, J., Despres, S., Sunamoto, M. and
Anpo, M., J. Phys. Chem., 95, 8813-18 (1991).

2) Anpo, M., Zhang, S. G., Higashimoto, S., Matsuoka, M., Yamashita, H., Ichihashi, Y., Matsumoto, Y. and Souma, Y., J. Phys. Chem. B, 103, 9295-301 (1999).

3) Yoshida, S., Tanaka, T., Nishimura, Y., Hiraiwa, T., Tanaka, T. and Funabiki, T., Proc. of the 13th Seminar on Sci. and Tech., Japan-Taiwan Catalysis Seminar (1990) pp. 185-95.

4) Baiker, A., Dollenmeier, P., Glinski, M., Reller, A. and Sharma, V. K., J. Catal., 111, 273-85 (1988).

5) Pichat, P., Herrmann, J.-M., Disdier, J. and Mozzanega, M.-N., J. Phys. Chem., 83, 3122-26 (1979).

6) Das, N., Eckert, H., Hu, H., Wachs, I. E., Walzer, J. F. and Feher, F. J., J. Phys. Chem., 97, 8240-43 (1993).

7) Morey, M., Davidson, A., Eckert, H. and Stucky, G., Chem. Mater., 8, 486-92 (1996).

8) Prakash, A. M. and Kevan, L., J. Phys. Chem. B, 103, 2214-22 (1999).

9) Catana, G., Rao, R. R., Weckhuysen, B. M., Van Der Voort, P., Vansant, E. and Schoonheydt, R. A., J. Phys. Chem. B, 102, 8005-12 (1998).

10) Dutoit, D. C. M., Schneider, M., Fabrizioli, P. and Baiker, A., J. Mater. Chem., 7, 271-78 (1997).

11) Sen, T., Ramaswamy, V., Ganapathy, S., Rajamohanan, P. R. and Sivasanker, S., J. Phys. Chem., 100, 3809-17 (1996).

12) Stiegman, A. E., Eckert, H., Plett, G., Kim, S. S., Anderson, M. and Yavrouian, A., Chem. Mater., 5, 1591-94 (1993).

13) Gao, X. and Wachs, I. E., J. Phys. Chem. B, 104, 1261-68 (2000).

14) Samuneva, B., Dimitrov, V., Dimitiev, Y., Chernev, V. and Gochev, G., J. Sol-Gel Sci. and Tech., 2, 913-15 (1994).

15) Devi, P. S. and Ganguli, D., J. Non-Cryst. Solids, 240, 50-54 (1998).

16) Gritscov, A. M., Shvets, V. A. and Kazansky, V. B., Chem. Phys. Lett., 35, 511-12 (1975).

17) Iwamoto, M., Furukawa, H., Matsukami, K., Takenaka, T. and Kagawa, S., J. Am. Chem. Soc., 105, 3719-20 (1983).

18) Tran, K., Hanning-Lee, M. A., Biswas, A., Stiegman, A. E. and Scott, G. W., J. Am. Chem. Soc., 117, 2618-26 (1995).

19) Kawashima, M. and Matsui, K., J. Ceram. Soc. Japan., 107, 282-84 (1999).

20) Kawashima, M., Oda, N., Uchida, Y. and Matsui, K., J. Lumin., 87-89, 685-87. (2000).

21) Bogomolova, L. D., Jachkin, V. A. and Krasil'nikova, N. A., J. Non-Cryst. Solids, 241, 13-26 (1998).

22) Dzwigaj, S., Matsuoka, M., Franck, R., Anpo, M. and Che, M., J. Phys. Chem. B, 102, 6309-12 (1998).

23) Dutoit, D. C. M., Schneider, M., Fabrizioli, P. and Baiker, A., Chem. Mater., 8, 734-43 (1996).

24) Curran, M. D., Gedris, T. E. and Stiegman, A. E., Chem. Mater., 11, 1120-27 (1999).

25) Livage, J., Chem. Mater., 3, 578-93 (1991).

26) Balzani, V. and Scandola, F., "Supramolecular Photochemistry," Ellis Horwood (1991) pp. 38-40. 